\title{
Psychology of compulsory detention
}

\author{
Allan Beveridge
}

The compulsory detention and treatment of patients against their will is unique to psychiatry. It is arguably the most stressful event in psychiatric practice, both for the doctor and for the patient, and yet, although much has been written about the details of mental health legislation (Clare, 1980; Fennell, 1995), very little has been said about the psychological impact that this procedure has on either the doctor or the patient (exceptions are Mills, 1962; Rogers et al, 1993). This paper will examine the emotional factors involved when a patient is deprived of his or her liberty, and will take as its point of reference the Scottish Mental Health Act.

Among psychiatrists there is a spectrum of attitudes towards compulsory detention. At one end there is the position, exemplified by Thomas Szasz, which views psychiatric intervention as an infringement of personal liberty. If, for example, a person wishes to kill himself, that is his right and no one should interfere. At the other end of the spectrum is the paternalist position, which holds that the doctor knows best. If the patient is behaving in a manner which the psychiatrist considers is irresponsible then it is quite legitimate to intervene. Underlying these positions are mutually opposing philosophical assumptions about the relationship between mind and body. The Szaszian perspective emphasises the free will of the individual, while the paternalist approach views the patient as impaired by a disease process and thus no longer fully responsible. Not only will psychiatrists vary as to which position they occupy along this spectrum, but each individual psychiatrist probably fluctuates in his or her response to particular patients, at times adopting a libertarian approach, at others, a paternalist one.

In making the decision whether to detain a patient, the doctor finds himself under a variety of different pressures. There may be demands from the patient's general practitioner. the family, the police or from hospital staff. The general attitudes of the wider community are changing from an anti-institutional, Laingian view of madness to a more interventionist approach, inspired by the case of Christopher
Clunis and other similar episodes, widely reported in the media. The doctor's most recent experience of detaining patients will also play a part, such that, if on the last occasion a patient. who was not detained, went on to commit a serious offence, then it is more likely that the doctor will play safe and opt for detention.

The doctor's dilemma can provoke a variety of different emotions. There may be anxiety as to whether he has made the right decision. The doctor may have felt frustrated by the patient's lack of cooperation with treatment, and the decision to proceed to detention may have been made in a spirit of anger or even with a desire to 'punish' the patient. There may be an element of manic defence on the part of the doctor in that he feels he is 'doing something' to sort out the problem. The doctor may approach the question with a sense that he is 'rescuing' the patient: where others have procrastinated or shied away from such a powerful intervention, the bold clinician steps in to save the day. There may be a feeling of relief that, at last, control has been taken of a worrying situation - the patient is in a safe haven, and the community is now out of danger.

After the procedure is completed the doctor may experience feelings of guilt. He may wonder if it was an appropriate use of power in what often appears to be an essentially unequal contest. The courts and the Mental Welfare Commission tend to side with the doctor and it is comparatively rare for a patient's appeal to be successful. His patient may emerge from the proceedings looking crushed, if not broken in spirit. The doctor may feel uneasy facing the patient again, and may avoid doing so. Alternatively, the doctor may have to contend with an angry. hostile patient, and this may also lead to avoidance. He may feel despondent about the change in the relationship with his patient, or he may feel anger towards the patient who does not seem to appreciate that the compulsory order was a means to help him - the doctor was, in effect, trying to save him from himself.

If the doctor experiences many different emotions, then so, too, does the patient, often to a more extreme degree. A common reaction. 
especially in the early stages, is that of denial. The patient vigorously denies that he is mentally ill. He may vehemently disagree with the statements in the certification papers, detailing the reasons for compulsory treatment. He may refute the account his relatives give of his recent behaviour and he may question the legitimacy of the whole procedure. Along with denial there is usually anger. The patient may be furious with the psychiatrist for signing the papers; with his relatives for telling tales about him; with the police for bringing him into hospital; and with anyone else involved in the committal procedure, such as mental health officers, nurses or friends. If the patient has been suffering from paranoid delusions then the committal procedure may confirm his view that he is being persecuted - it seems that they really are out to get him.

The patient is often very frightened as he tries to come to terms with this radical change in his day-to-day life. He is fearful about the implications of being detained: will he be locked up for ever? Will he be subjected to physical coercion? Will he be given drugs or ECT against his will? He may never have been in a psychiatric hospital, and his perception may have been shaped by some of the more lurid images of 'madhouse' in the media.

The experience of being declared a suitable case for compulsory treatment often leads to a crisis of self-identity. He has been judged insane and publicly certified as unfit to function in society. This can come as a major blow to his self-esteem, and can force a re-evaluation of his image of himself and his relation to others. Understandably, depression frequently follows. Many of the emotions felt by the detained patient (denial, anger and depression) are similar to those felt during the course of bereavement. This is not surprising because the patient is actually dealing with loss: the loss of his self-esteem and the loss of his freedom.

Feelings of depression are compounded by the new situation in which the patient now finds himself. From the familiarity of the home he has been forced into the strange and unsettling world of the psychiatric hospital. He has to contend with the compulsory cohabitation with strangers, the repeated enquiries into his life story, and the rules and regulations of institutional living. He may feel hopeless about his predicament, especially if his appeal against the detention is turned down. Added to all this, there may be the gradual realisation that he is actually mentally ill. Sometimes, however, the patient experiences the detention in a more positive light. He may feel that he is now being cared for; he may have dimly recognised that he was unwell, and it is something of a relief that he has, at last, found help. The fact that staff have applied for a compulsory order demonstrates their commitment to him. Like good parents, they are setting limits on his behaviour, and this may instil a sense of security.

The different types of compulsory order cause particular problems for the doctor and the patient. The emergency order (Section 24/25) requires the doctor to make his mind up quickly. The emotional environment is likely to be charged, with a clamour from relatives or staff for something to be done. It is often a junior doctor who is called upon to make the decision. and typically the situation arises out of working hours when the trainee is on his own. The patient is frequently unknown to the doctor, and information may be difficult to gather. The patient may be aggressive or mute, or he may not speak English. The doctor has to rely on the testimony of others, such as relatives or the police, and he will have to decide how trustworthy or accurate these accounts are: for example, do the relatives simply want rid of a troublesome family member? The junior doctor has a duty to inform the mental health officer, and although there is also a consultant with whom he can discuss the decision there is frequently a culture of not wanting 'to bother' the senior, so the most drastic intervention in psychiatric practice - depriving someone of their liberty - is often made by the least experienced member of the team.

At the time of the emergency detention the patient is often disturbed and in high state of arousal. He may not understand what is going on, or fully appreciate the implications of the compulsory order. New patients are usually unfamiliar with the Mental Health Act and often find it difficult to accept that they can be 'shut up in hospital' as a result of the signing of a piece of paper. They often face a chorus of people, including their own family, declaring that they should be put away. If the patient has to be taken from his home he may have to face the indignity of being removed by the police, and this may take place in full view of the neighbours. Unsurprisingly, the patient can often feel like a criminal.

The problem for the doctor when considering the subsequent 28-day order (Section 26) is that of reaching a decision within 72 hours. The decision, in part, rests on whether the doctor feels he can trust the patient to stay and take medication. This has implications for his therapeutic relationship with the patient. If he proceeds with the 28-day order, he may be giving a clear signal to the patient that he does not trust him; if he does not proceed, and the patient disappears, he may feel foolish, let down, or even angry. From the patient's point of view, he is still coming to terms with the first order when he is being asked to consider the prospect of a further period of detention. There will be more interviews, and this time the mental health officer is 
asking to see his family. He may have fallen out with his relatives as a result of the initial detention, and he may not relish the idea of his family talking about him behind his back.

The six-month order (Section 18) is a major procedure for both doctor and patient, involving the sheriff court. The doctor has to complete his part of the section papers in the knowledge that his statement will be read both by his patient and by the legal authorities. The demands of these two audiences are rather different. In discussions with the patient about his illness the doctor may have avoided potentially threatening terms, such as 'schizophrenia', because he considers that the patient is not ready to deal with it. The doctor may have also avoided the term 'delusion' because it upsets the patient and leads to arguments.

In court, he finds that it is just such terminology which impresses the sheriff, who is looking for unequivocal evidence that the patient is mentally ill. The doctor thus has to prepare a written application which takes account of these competing needs. Inevitably, in the desire to make a convincing case he has to describe the patient in language that is more direct than he may like. The doctor may also have to appear in the witness stand, in front of the patient, to answer questions about sensitive matters. Again the doctor will have to adopt the rather less tactful language of the legal world in order to make the medical case for detention. As he speaks he may witness the distress his words are having on his patient.

From the patient's perspective the whole procedure can be very intimidating, and many patients do not contest the application. If the doctor feels uneasy in court it is much worse for the patient. Because of the legal setting, he can, once again, feel like a criminal. Those patients who do go into the witness stand often become more disturbed under the stress of putting forward their case, and the experience can be profoundly traumatic and humiliating. Hearing that their most deeply held beliefs are 'delusions', or that they are considered to be unfit to look after themselves, can greatly undermine their self-worth. The duration of the court order (six months) can seem like a very long time indeed.

This paper has briefly examined the psychological and emotional factors involved for both doctor and patient, when compulsory detention is considered. Such an intervention raises a host of ethical, philosophical and personal issues, and it can be a highly stressful procedure for both parties. Prins (1986) has described training programmes for mental health workers in England which address some of these issues, while, more recently, in Scotland, the Scottish Division of the Royal College of Psychiatrists, in conjunction with the Mental Welfare Commission and the Scottish Office, has set up a training course in the use of the Mental Health Act. These courses may go some way to improve practice and to stimulate discussion of the dilemmas involved in compulsory detention. It would be especially useful if patients themselves participated in such ventures.

\section{References}

Clare, A. (1980) Psychiatry in Dissent (2nd edn). London: Routledge.

FENNELl, P. (1995) Treatment Without Consent: Law Psychiatry and the Treatment of Mentally III People Since 1845. London: Routledge.

MILLS, E. (1962) Living with Mental Illness. London: Routledge and Kegan Paul.

PRINS, H. (1986) Dangerous Behaviour, the Law, and Mental Disorder. London: Tavistock.

Rogers, A., PILGRIM, D. \& LACEY, R. (1993) Experlencing Psychiatry: Users' Views of Services. London: Mind.

Allan Beveridge, Consultant Psychiatrist, Queen Margaret Hospital, Whitefield Road, Dunfermline KY12 OSU 